\title{
O caminho, a experiência e a aventura*
}

\author{
Marcelo Rodrigues Souza Ribeiro \\ Faculdade Cambury
}

\section{Resumo}

Acompanhando o itinerário demarcado pelas palavras do título, o artigo se divide em quatro partes. Na primeira, após um prelúdio sobre os escritos de Georg Simmel, o tema do milagre do caminho como diferença do humano em relação ao animal orienta, por meio de uma interrogação histórica, um questionamento sobre o conceito de vida na modernidade. Na segunda, a questão da modernidade é desdobrada em torno do motivo da destruição ou expropriação da experiência, tal como discutido por Simmel e Walter Benjamin (entre outros). Na terceira, uma leitura de A aventura, ensaio de 1911 de Simmel, possibilita interrogar a colonialidade como condição da modernidade. Na quarta, retomando a questão da diferença entre humano e animal em relação à discussão sobre aventura, colonialidade e modernidade, esboça-se uma compreensão do conjunto das narrativas de Tarzan como exemplo paradigmático de narrativas de aventura coloniais-modernas que, ademais, articulam discursos sobre a diferença entre humano e animal.

Palavras-chave: Aventura; modernidade colonial; animalidade; Tarzan.

\begin{abstract}
Following the itinerary of the words in the title, this article is divided into four parts. In the first one, after a prelude on the writings of Georg Simmel, the motif of the path's miracle as difference of the human in relationship to the animal guides, by means of a historical interrogation, a questioning about the concept of life within modernity. In the second part, the question of modernity is unfolded around the motif of the destruction or expropriation of experience, as it is discussed by Simmel and Walter Benjamin (among others). In the third part, a reading of The Adventure,

\footnotetext{
Path, experience and adventure

' Endereço para correspondências: Faculdade Cambury, Av. T2, n 3531 , St. Sol Nascente, Goiânia, GO, 74410-220 (marcelo_rsr@yahoo.com).
} 


\section{HüMANAS}

a 1911 essay by Simmel, allows us to interrogate coloniality as a condition of modernity. In the fourth part, taking the question of the difference between human and animal in relationship to the discussion of adventure, coloniality and modernity, I suggest an understanding of the narratives of Tarzan as a paradigmatic example of colonial-modern adventure narratives which, furthermore, articulate discourses about the difference between human and animal.

Keywords: Adventure; modernity; coloniality; animality; Tarzan.

\section{1 - O milagre do caminho e a vida na modernidade}

Tma tensão entre um pensamento histórico sobre a modernidade e um pensamento formal sobre a vida social perpassa os escritos de Georg Simmel. Qualquer leitura de Simmel passa, mesmo (e talvez sobretudo) quando não é capaz de anotá-lo às margens do texto, por uma tensão correspondente entre um reconhecimento sócio-antropológico da particularidade de seu pertencimento histórico-cultural e uma deriva filosófica que liga sempre o detalhe mais ínfimo e evanescente, a efemeridade mais residual, à problemática mais permanente, à opacidade que resta mais geral, mais universal.

Quando aborda a concretude de um objeto cotidiano - uma porta ou uma ponte, a asa de um jarro ou a moldura de um quadro, para ficarmos apenas com alguns exemplos-Simmel se demora na articulação entre a singularidade do uso e a recorrência da forma. A essa demora no efềmero e único mas iterável e repetível, a essa morada na ponte, corresponde um hábito metodológico que Simmel cultivou de forma mais ou menos intensa no decorrer de sua obra e que se tornou sempre e cada vez mais cristalino: a atenção ao detalhe e ao que é geralmente posto à margem como princípio de leitura.

Tanto nas tensões que o habitam quanto nas moradas que habita de passagem, Simmel não é, contudo, solitário. O método simmeliano parece indicar sua relação dialógica com uma comunidade inconclusa, cujo domínio conceitual Carlo Ginzburg (1990) denominou "paradigma indiciário". Embora esta seja uma denominação um tanto paradoxal - já que, como Ginzburg reconhece, são "formas de saber tendencialmente mudas" e "suas regras não se prestam a ser formalizadas nem ditas" (1990, p. 179) - e, em Simmel como em outras partes, seja impossível delimitar um tal paradigma de modo estável e unificado, 
O caminho, a experiência e a aventura

Marcelo Rodrigues Souza Ribeiro

inscrever a leitura que pretendo esboçar de alguns textos de Simmel no marco do "paradigma indiciário" possibilita demarcar um horizonte teórico de intertextualidade e abrir espaço, às margens, para anotar as singularidades do itinerário.

É no cerne da tensão entre um pensamento do particular e do concreto e uma deriva filosófica em direção à abstração que se torna legível, em $A$ ponte e a porta (ensaio publicado em 1909), a argumentação de Simmel sobre a diferença entre o humano e o animal:

A construção de estradas é de certa maneira uma prestação especificamente humana; o animal também não deixa de superar distâncias, e sempre do modo mais hábil e mais complexo, mas ele não faz ligação entre o começo e o fim do percurso, ele não opera o milagre do caminho: a saber, coagular o movimento por uma estrutura sólida, que parta dele. (SIMMEL, 1996; p. 11)

Não é a primeira nem será a última vez que Simmel faz referência à diferença entre humano e animal. No mesmo ensaio, alguns parágrafos antes, ele afirma, numa linguagem mais abstrata, que "Só ao homem é dado, diante da natureza, associar e dissociar [...]" (idem, p. 10). A ponte e a porta como formas de relação com o espaço e com o percurso de distâncias condensam objetivamente um sinal diacrítico do humano, o milagre do caminho, respondendo assim à questão filosófico-antropológica da diferença entre humano e animal.

O que qualifica a vida humana como tal, para Simmel, é a potência positiva ou negativa do socius: associando e dissociando, o ser humano ultrapassa e engloba o círculo da natureza e se constitui em contraposição a ele. A figura do animal e a figura do homem permanecem em contraponto, assim como desde Aristóteles se contrapõem zoé e bios, a vida do vivente em geral e a vida humanamente qualificada - a vida nua e a existência política, nos termos de Giorgio Agamben (2002, p. 9-20). Essa duplicidade do tema da vida, entre humano e animal, pode ser rastreada em Simmel através do tema do milagre do caminho, entendido como uma operação que diferencia o humano do animal.

Como argumenta Jonatas Ferreira (2000), na obra de Simmel, "nenhuma idéia está investida de maior centralidade teórica que a idéia de vida, 
mais precisamente, da vida tal como ela é experienciada nas sociedades modernas" (p. 106). A centralidade do problema da vida na modernidade, em Simmel e além dele, deve ser interrogada metafísica, filosófica, sociológica e historicamente. Para Jonatas Ferreira (2000), Simmel se diferencia do vitalismo que toma forma em Henri Bergson:

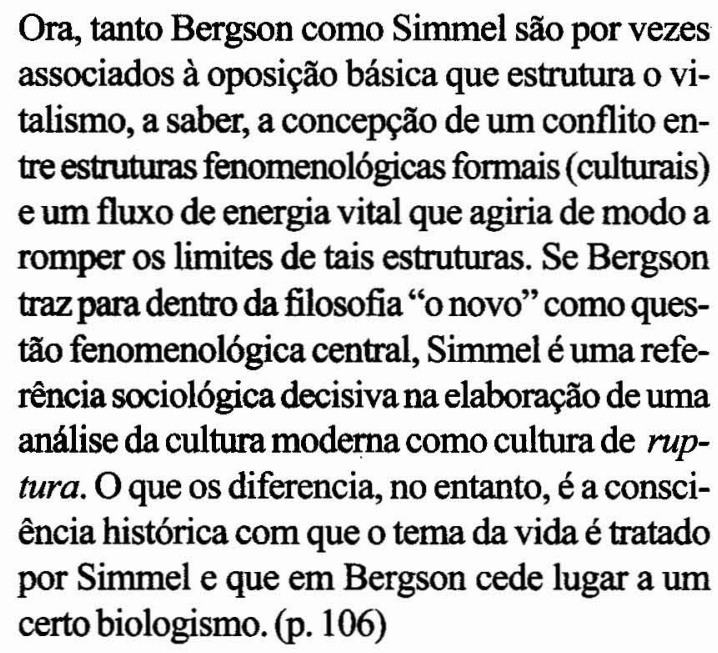

Pode ser interessante fazer reverberar e ressoar a "consciência histórica" de Simmel sobre o tema do milagre do caminho, exacerbando a tensão entre o histórico e o formal. O milagre do caminho, entendido por Simmel como o próprio do humano em oposição ao animal, se tinge com as colorações e conotações históricas do espaço-tempo da modernidade. Situar o tema do milagre do caminho na modernidade é um gesto de leitura que se justifica devido ao reconhecimento (caro a Simmel) da temporalidade e da historicidade como condições ontológicas e epistemológicas.

Que objetos dão forma, na modernidade, ao milagre do caminho? Como esses objetos reinscrevem, concretamente, a problemática da diferença entre humano e animal, levando-nos de uma questão filosófica aparentemente abstrata a suas implicações históricas aparentemente concretas? No universo imagético que vai, por exemplo, do quase-mítico trem que chega à estação diante do cinematógrafo dos irmãos Lumière às ferrovias de $O$ homem com a câmera, de Dziga Vertov (1929), podemos decifrar uma série de conotações históricas que lançam um complexo jogo de luzes e sombras sobre o tema do milagre do caminho. 
O caminho, a experiência e a aventura

Marcelo Rodrigues Souza Ribeiro

O trem aparece como um dos signos modernos da integração territorial e da consolidação dos Estados-Nação. A abertura de estradas e a extensão de linhas telegráficas, no caso brasileiro, também insinuam as dimensões políticas do milagre do caminho. Pensemos na estrada que cinde a pureza Nambiquara, na "Lição de Escritura" dos Tristes Trópicos, de Claude LéviStrauss. Pensemos também nos filmes do Major Luiz Thomas Reis e em suas condições de produção, como parte das atividades da Comissão Rondon na ligação de linhas telegráficas. Pensemos ainda como, em toda a África, a abertura de estradas, a construção de ferrovias e a exploração do interior através da navegação constituem o caminho como signo da colonização. Em todos esses contextos, o percurso do caminho se dá a partir de um centro de poder - o Estado-Nação como potência colonizadora tanto interna quanto externamente, por assim dizer - e se estende até um espaço afastado que é assim integrado aos circuitos políticos e econômicos centrais.

Assim, o tema do milagre do caminho entretece a problemática da diferença entre animalidade e humanidade e a problemática da condição humana na modernidade mundial através da questão do percurso: como uma agulha, do começo ao fim, o traçado do caminho coagula o movimento da modernidade mundial - entre centros e periferias, nos espaçamentos geopolíticos do colonialismo. Figurando a definição da vida humanamente qualificada através da metonímia do milagre do caminho, emerge a pergunta: o que se torna a vida humana - e a vida animal, no negativo do argumento - quando observada através das novas constelações de significação que tingem o tema do caminho a partir da modernidade? Ou seja, o que é a vida na modernidade? Como a modernidade diferencia e relaciona, destece e entretece, na vida, o humano e o animal?

\section{2 - Modernidade e destruição da experiência: a tragédia da cultura}

A modernidade advém como uma questão sobre a vida humana e vem interrogar a própria vida de uma forma geral. Na interrogação da vida moderna, entram em jogo categorias como a alienação, o inconsciente, o desejo, entre outras, em tentativas de comentar e enquadrar as ansiedades que circundam diversos fenômenos, como a urbanização, a industrialização, a burocratização, a proletarização etc. Discutindo o conceito de vida em Simmel, Jonatas Ferreira (2000) afirma: 


\section{HÜMANAS}

Parece significativo o fato de que a produção de instrumentos, o estabelecimento de um intermediário entre desejo e fruição, esteja na base de uma mudança que instaura o processo de humanização do ser humano: a passagem de uma relação direta entre o "animal humano" e a natureza para uma relação indireta: ser humano-meios-fins. [...] A emergência da vida como problema filosófico e existencial, assim, é produto de um processo em que uma estrutura tecnológica mediativa torna-se progressivamente complexa, separando mais e mais o desejo humano da possibilidade de fruição. Tempo, consciência, causalidade são formas de manifestar esta fissura no ser. Em outras palavras, tanto mais a perspectiva de fruição escapa num labirinto de relações sociais e produtivas, tanto mais a vida constitui-se como problema ontológico. (FERREIRA, 2000; p. 107)

A separação entre desejo e fruição - elemento constitutivo da vida humana (e sinal diferenciador do humano em relação ao animal para toda uma tradição filosófica) - se potencializa com um dos eventos paradigmáticos da época moderna: a destruição ou expropriação da experiência. Tema caro a toda a tradição crítica que culmina em pensadores como Theodor Adorno e, sobretudo, Walter Benjamin, a destruição da experiência na época moderna passa pela emergência do desejo como uma categoria central de compreensão da vida humana - da filosofia hegeliana do Espírito à psicanálise freudiana. Como argumenta Giorgio Agamben (2005), o desejo se torna "a idéia de uma inapropriabilidade e inexauribilidade da experiência" (p. 34-5) e, nos termos de Simmel, se distancia da fruição. O desejo se vincula à "fantasia, insaciável e incomensurável" e se diferencia assim da necessidade, vinculada à "realidade corpórea, mensurável e teoricamente satisfazível" (Agamben 2005, p. 36). A modernidade aparece assim, já em Simmel, como uma época da desproporção: conforme Ferreira, reconhece-se a "vida moderna como dinâmica de desproporção e portanto de contingência" (FERREIRA, 2000; p. 106).

Em $O$ conceito e a tragédia da cultura (ensaio de 1911), Simmel escreve sobre "a situação problemática típica do homem moderno": 


\section{O caminho, a experiência e a aventura}

Marcelo Rodrigues Souza Ribeiro

[...] o sentimento de ser circundado por inúmeros elementos culturais que não lhe são desprovidos de significação, mas que também não são, em seu fundamento, plenos de significação - elementos culturais que no conjunto possuem algo de opressivo, porque ele não pode assimilar interiormente a todos individualmente, e tampouco pode simplesmente descartá-los, uma vez que eles pertencem potencialmente à esfera de seu desenvolvimento cultural. Poder-se-ia caracterizar isso com a inversão da frase que qualificava os primeiros franciscanos em sua pobreza serena, em sua absoluta libertação de todas as coisas, que de alguma maneira conduziriam o caminho da alma através de si e fariam dele um caminho indireto: nihil habentes, omnia possidentes em vez disso, os homens de culturas muito ricas e sobrecarregadas omnia habentes, nihil possidentes. (SIMMEL, 1998; p. 105)

O homem moderno metropolitano ressoa em diversos momentos da obra de Simmel com conotações bastante afins às que a figura recebe nas obras de contemporâneos como Walter Benjamin, por exemplo. O que se ressalta dessa forma é a conformação de uma idéia da modernidade como mo(vi)mento de transbordamento e cultura de ruptura, a "tese do caráter negativo, sem repouso e contingente da vida moderna" (FERREIRA, 2000; p. 107).

Mas se a modernidade aparece como uma ruptura em relação ao passado, ela não se dá, contudo, a partir de fora, como uma força que perturba uma ordem tradicional e instaura a contingência da desordem e da desproporção. Para Simmel, a destruição da experiência advém como um processo endógeno à cultura de sua época, resultado de forças próprias e profundas ligadas à essência mesma da cultura. Simmel parece assim compreender a "situação problemática típica do homem moderno" como uma espécie de instância extrema da "tragédia própria da cultura":

[...] como destino trágico - em contraposição ao triste ou ao que destrói a partir de fora - entendemos o seguinte: que as forças aniquiladoras dirigidas contra uma essência brotam das camadas mais profundas desta mesma essência; 


\section{Hümânas}

que com a sua destruição se consuma um destino que já estava instalado nela mesma e que o desenvolvimento lógico constitui justamente a estrutura com a qual a essência construiu sua própria positividade. (SIMMEL, 1998;p. 103-4)

A vida na modernidade se inscreve sob o signo da expropriação ou destruição da experiência como tragédia moderna da cultura. A possibilidade de experienciar os diversos elementos culturais que compõem a modernidade foi expropriada dos homens modernos, que tudo têm a sua disposição, em meio às torrentes urbanas de mercadorias, pessoas, imagens e sensações, mas nada podem ou conseguem possuir.

A modemidade instaura, portanto, a paradoxal experiência da destruição ou expropriação da experiência. O momento histórico que veio simbolizar de forma emblemática essa situação foi a Primeira Guerra Mundial. Em um conciso e contundente ensaio de 1933, Experiência e pobreza, Walter Benjamin condensa a problemática:

Uma geração que ainda fora à escola num bonde puxado por cavalos viu-se abandonada, sem teto, numa paisagem diferente em tudo, exceto nas nuvens, e em cujo centro, num campo de forças de correntes e explosões destruidoras, estava o frágil e minúsculo corpo humano. (BENJAMIN, 1994; p. 115)

Mas se a Primeira Guerra Mundial simboliza, como uma espécie de caricatura perversa, a experiência da destruição da experiência, o processo que leva à intensificação dessa ansiedade moderna se estende desde muito antes $\mathrm{e}$ permanece ainda em curso, relacionando-se aos desenvolvimentos técnicos que cada vez mais tomam conta da vida cotidiana. Benjamin afirma, na seqüência da citação anterior: "Uma nova forma de miséria surgiu com esse monstruoso desenvolvimento da técnica, sobrepondo-se ao homem." (1994; p. 115).

No entanto, o que parece ser uma ênfase no caráter negativo da modernidade encerra também seus deslumbramentos. O ensaio de Benjamin é bastante significativo a esse respeito. Após descrever a "miséria" que se abateu sobre o "homem moderno", Benjamin pergunta: "qual o valor de todo o nosso patrimônio cultural, se a experiência não mais o vincula a nós?”(1994;p. 115). 
Em seguida, Benjamin descreve a situação como "uma nova barbárie", para, em suas palavras:

[...] introduzir um conceito novo e positivo de barbárie. Pois o que resulta para o bárbaro dessa pobreza de experiência? Ela o impele a partir para a frente, a começar de novo, a contentar-se com pouco, a construir com pouco, sem olhar nem para a direita nem para a esquerda. (BENJAMIN, 1994; p. 116).

\section{3 - A aventura como suplemento experiencial e a colonialidade da época moderna}

Se qualquer leitura de Simmel envolve uma tensão entre historicidade e forma, qualquer leitura de seu ensaio de 1911 sobre $A$ aventura passa necessariamente por uma duplicidade. É preciso reconhecer, por um lado, a ênfase de Simmel no caráter formal da aventura, em sua condição de "forma de experiência", independente, em princípio, dos conteúdos da experiência. Por outro lado, é necessário também pensar a historicidade da noção de aventura, seus contextos e intertextos, no que é possível denominar uma "antropologia da aventura" (cf. VIVANCO \& GORDON, 2006).

A pergunta que orienta minha leitura de $A$ aventura é: qual é o estatuto da noção de "aventura" no momento histórico da modernidade? Essa pergunta se desdobra em pelo menos algumas outras: a que conteúdos históricos a noção de aventura como forma está (ou esteve, então) tendencialmente vinculada? Como a noção de aventura se dissemina através de diferentes contextos? Que conotações tem a noção de aventura e que valor ela assume em cada um desses contextos e na sua passagem através deles?

Uma vez que Simmel elabora uma visão formal da aventura como aquilo que "extrapola o contexto da vida" (SIMMEL, 1998; p. 171), interrogar os contextos e intertextos da noção de aventura passa por pensar as formas pelas quais se dá a extrapolação do contexto da vida. Simmel escreve:

[...] a aventura, segundo sua essência e encanto específicos, é uma forma da experiência. $\mathrm{O}$ conteúdo do acontecer não constitui ainda a aventura. Esta se caracterizará somente por meio de uma certa tensão do sentimento de vida, 


\section{HUMANAS}

com a qual aqueles conteúdos se realizam; somente quando uma corrente, indo e vindo entre a parte mais exterior da vida e a sua fonte central de energia, abarca aquela em si, e quando aquela coloração, temperatura e ritmo especiais do processo de vida constituem o que é verdadeiramente decisivo, o que de certa maneira acentua o conteúdo de um tal processo de vida, o acontecimento deixará de ser uma simples experiência e se tornará uma aventura. (SIMMEL, 1998; p. 182)

$\mathrm{Na}$ época moderna, caracterizada pela ansiedade em relação à expropriação ou destruição da experiência, a aventura parece suprir uma falta, uma lacuna e uma ausência (de experiência), constituindo no entanto algo a mais, uma outra coisa, um excesso, um transbordamento e um redobramento, uma extrapolação através de um desvio. Como argumenta Simmel,

Ao situar-se fora do contexto da vida, a aventura como que penetra, justamente com esse mesmo movimento, novamente nele [...]. Ela é um corpo estranho em nossa existência, que, no entanto, é de alguma forma ligado ao centro. O externo é, mesmo via um longo e não habitual desvio, uma forma do interno. (SIMMEL, 1998; p. 172)

Simmel enfatiza que a aventura é uma forma de experiência e pode portanto se concretizar com vários conteúdos. No entanto, ele mesmo nota que "o conteúdo erótico tende, antes de todos os demais, a assumir esta forma, de tal modo que nossa linguagem praticamente impede a aventura de ser entendida como algo diferente de uma experiência erótica" (SIMMEL, 1998; p. 179). Simmel também nota o "fato de a relação amorosa normalmente ser considerada apenas para o homem 'aventura', sendo que para a mulher algo idêntico é enquadrado em outras categorias" (1998; p. 180). ${ }^{2}$

\footnotetext{
2 É impressionante a consonância dessa observação simmeliana com o título e o teor de uma narrativa de aventura autobiográfica escrita por Osa Johnson sobre sua vida com o marido, Martin Johnson: Casei-me com a aventura (1957).
} 


\begin{abstract}
Além disso, Simmel situa a aventura como um elemento mais apropriado à juventude $\mathrm{e}$ a uma disposição romântica diante da vida do que à velhice e a uma disposição histórica. Referindo-se ao 'típico 'fatalismo' do aventureiro", Simmel escreve: "Na aventura, [...] apostamos tudo justamente na chance flutuante, no destino e no que é impreciso, derrubamos a ponte atrás de nós, adentramos o nevoeiro, como se o caminho devesse nos conduzir sob quaisquer circunstâncias" (SIMMEL, 1998; p. 178).

Portanto, Simmel relaciona a forma da aventura a uma série de conteúdos de vida. O caminho da aventura - que "tem começo e fim"(SIMMEL 1998, p. 172) - passa por certos itinerários privilegiados - o erotismo, a juventude, a disposição romântica, a masculinidade etc. O caminho da aventura se abre através de um movimento duplo: de um lado, extrapolação do contexto da vida e, de outro lado, retorno ao cerne mesmo da vida. Agamben (2005) argumenta que a expropriação da experiência na época moderna é correlata à emergência da aventura "como o último refúgio da experiência" (p. 39). Assim, diz ele, "a aventura pressupõe que haja um caminho para a experiência e que este caminho passe pelo extraordinário e pelo exótico (contraposto ao familiar e ao comum)" (2005; p. 39). Como "último refúgio da experiência", a aventura extrapola o contexto da vida através de um desvio pelo exótico e pelo extraordinário, retornando ao cerne mesmo da vida na modernidade como um suplemento à expropriação da experiência. Assim, a aventura, na história da modernidade mundial, aparece como o caminho suplementar que coagula o movimento entre o contexto da vida e outros contextos - centro e periferia, metrópole e colônia, Ocidente moderno e alteridade colonial.

Embora Simmel relacione a aventura a certos conteúdos privilegiados, em nenhum momento ele interroga explicitamente sua relação com a experiência colonial. Aqui, o percurso da aventura se dá através do espaçamento geopolítico do colonialismo e aparece como a extrapolação do contexto da vida na modernidade - definido pela expropriação da experiência - em direção à alteridade investida como reserva experiencial. Tudo se passa como se à expropriação da experiência - que inscreve a vida na modernidade sob o signo problemático da tragédia da cultura - se adicionasse, como um ambivalente suplemento, um desvio pelo exótico e extraordinário - que tem no espaçamento colonial seu locus privilegiado.
\end{abstract}




\section{HUMANAS}

Trata-se do espaço imaginário das narrativas de aventura, que vieram a se disseminar torrencialmente a partir da experiência colonial do exótico e do extraordinário. É notável, a esse respeito, a importância do erotismo nas narrativas de aventura e na forma de conceber a experiência colonial, que aparece como conquista e penetração. A inscrição moderna da aventura como suplemento experiencial se dramatiza através do espaçamento colonial. No cerne vital da modernidade, por movimentos históricos diversos, a expropriação da experiência e a aventura se colocam numa relação de suplementariedade - o suplemento da aventura é aquilo que vem se adicionar à "falta" de experiência como que para completá-la mas é já um excesso, uma outra coisa que não se encaixa exatamente, um transbordamento. A modernidade se constitui por e como esse transbordamento. Só há modernidade a partir do suplemento transbordante da aventura e da experiência colonial.

\section{4 - As narrativas de Tarzan}

Walter Benjamin caracteriza o que chama de "pobreza de experiência" dos "homens modernos" de forma similar a como Simmel descreve a "tragédia da cultura", sugerindo que se trata de uma espécie de saturação: "eles 'devoraram' tudo, a 'cultura' e os 'homens', e ficaram saciados e exaustos" (BENJAMIN, 1994; p. 118). Em seguida, ele parece descrever a atmosfera ideológica que circunda a emergência de fantasias como as narrativas de Tarzan:

Ao cansaço segue-se o sonho, e não é raro que o sonho compense a tristeza e o desânimo do dia, realizando a existência inteiramente simples e absolutamente grandiosa que não pode ser realizada durante o dia, por falta de forças. A existência do camundongo Mickey é um desses sonhos do homem contemporâneo. É uma existência cheia de milagres, que não somente superam os milagres técnicos como zombam deles. [...] A natureza e a técnica, o primitivismo e o conforto se unificam completamente, e aos olhos das pessoas, fatigadas com as complicaçðes infinitas da vida diária e que vêem o objetivo da vida apenas como o mais remoto ponto de fuga numa interminável perspectiva de meios, 


\section{O caminho, a experiência e a aventura Marcelo Rodrigues Souza Ribeiro}

surge uma existência que se basta a si mesma, em cada episódio, do modo mais simples e mais cômodo [...]. (BENJAMIN, 1994; p. 118-119)

A existência de Tarzan parece se dar como um sonho moderno, assim como Mickey. Em cada um dos romances de Edgar Rice Burroughs, em cada um dos episódios de programa radiofônico ou das matinês cinematográficas seriadas, em cada um dos episódios das histórias em quadrinhos, em cada capítulo das séries televisivas e em cada um dos filmes, Tarzan repetidamente personifica um herói que "zomba" dos "milagres técnicos", no espírito de uma postura antimoderna que, como argumenta David Bradburd (2006), permeia a cultura da passagem entre o século XIX e o século XX e se prolonga em "valores antimodernos" com diferentes inflexões no decorrer do século XX como um todo. Em todas as suas aparições multimidiáticas, Tarzan escapa das "complicações infinitas da vida diária" com a força e a destreza de um herói idealizado em contraposição à experiência da destruição ou expropriação da experiência. Tudo se passa, recorrentemente, como se sua existência se bastasse a si mesma, no comando de um território selvagem cravado no interior de uma África imaginária.

As aventuras de Tarzan aparecem assim como suplementos experienciais, inscrevendo no cerne da modernidade um espaçamento colonial por uma África imaginada. Como afirma Robert Gordon:

As an icon Tarzan both transcends and highlights the specificity of adventure's historical meanings. In their day, Edgar Rice Burroughs's novels enjoyed enormous popularity because Tarzan represented the consummate colonial-era adventurer: a white man whose noble civility enabled him to communicate with and control savage peoples and animals. Tarzan is now the consummate "eco-tourist": a cosmopolitan striving to live in harmony with nature, using appropriate technology, and helping the natives who are too dumb to solve their own problems. Tarzan is still an icon of adventure, because like all adventurers, 
his actions have universal qualities [...]. But the meanings assigned to his adventurous actions, as with any adventure, are also highly dependent on specific historical, cultural, and political contexts. (GORDON, 2006; p. 9)

Tarzan aparece como um "ícone" crucial para pensar a aventura, pois se situa no cerne de uma tensão entre "qualidades universais" e "contextos específicos" - análoga de certa forma à tensão entre a consideração de problemáticas gerais e a atenção a detalhes e singularidades nos ensaios de Simmel.

A aventura passa pelo percurso de um caminho, tem começo e fim, aparece como uma totalidade. Uma temporalidade retrospectiva parece ser uma condição de possibilidade para que a aventura possa surgir. Seu surgimento, ademais, como totalidade, toma uma forma semelhante à da obra de arte, segundo Simmel, o que aponta para a constituição da aventura como uma reserva narrativa. As narrativas de aventura são a forma de disseminação do suplemento experiencial que constitui a modernidade como colonialidade. As narrativas de Tarzan acrescentam a condição de movimentarem discursos sobre a diferença entre humano e animal. O suplemento experiencial das narrativas de Tarzan passa não apenas pela inscrição de um espaçamento colonial no cerne da modernidade, mas também por uma aproximação à figura do animal em geral.

As aventuras de Tarzan passam necessariamente pela reiteração de uma diferença que é, contudo, repetidamente colocada em questão: a diferença entre o humano e o animal. As narrativas de Tarzan em geral movimentam, de um lado, um imaginário moderno do "homem-macaco", caracteristicamente evolucionista, e, de outro, reutilizam elementos de um imaginário mítico sobre "crianças selvagens", que remete a tempos mais antigos. Em Tarzan of the Apes, que inaugura o personagem em 1912, uma boa parte da narrativa trata da perturbação da diferença entre humano e animal que a figura de Tarzan condensa. Nessa e em outras histórias, a instabilidade da fronteira se manifesta recorrentemente e as ansiedades em torno de sua transgressão constante podem ser consideradas um dos ingredientes do sucesso massivo do personagem.

$\mathrm{Na}$ história de 1912, a diferença entre humano e animal acaba reafirmada, em última instância, através de uma tecnologia bastante significativa da modernidade: a análise de impressões digitais. No entanto, 
em todo o percurso secular de Tarzan em diversas mídias, a fronteira entre humano e animal permanece sendo colocada em questão-em imagens idílicas de comunicação e comunhão com a natureza ou em pesadelos de mistura e contaminação-e reafirmada, refeita, reiterada. Nos filmes, por exemplo, uma espécie de zoológico imagético ocupa recorrentemente a tela, reforçando a diferença entre humano e animal ao garantir aos espectadores o direito de olhar.

Tomando esse zoológico imagético como metonímia da maquinaria que procura (re)produzir a diferença entre humano e animal, é notável que um procedimento análogo também habita as imagens dos filmes quando se trata da alteridade colonial. Uma espécie de zoológico humano (cf. BANCEL et al., 2004) enquadra "os nativos" como objetos de um olhar filmico que não é o deles, reconstituindo a diferença entre "civilizado" e "primitivo" que é tão importante na modernidade e na construção da imagem do "nobre selvagem", crucial para o primitivismo de Tarzan.

O milagre do caminho, próprio do humano, se investe de uma controversa concretude sob as formas dos transportes e comunicações modernos (ferrovias, rodovias, linhas telegráficas etc.). A vida humana na modernidade traça seus caminhos em contraposição a diversas alteridades: num nível, o milagre do caminho permanece um sinal diacrítico em relação à alteridade animal; em outros níveis, as formas modernas do milagre do caminho passam pela contraposição do "homem moderno" às diversas formas da alteridade colonial. Amesma maquinaria que (re)produz, performativamente, a diferença entre humano e animal também (re)produz, performativamente, a diferença colonial, embora a operação que traça cada uma dessas fronteiras não seja a mesma e não tenha os mesmos efeitos.

Como produto da época moderna e de suas persistentes ansiedades em relação à destruição da experiência, como uma fabricação da "cultura do colonialismo" (cf. THOMAS, 1994) e uma herança colonial em tempos ditos póscoloniais, como uma ficção que orbita a questão da fronteira entre humano e animal por meio de um trabalho imaginativo em torno da figura do homemmacaco, Tarzan, suas narrativas e seu mundo fantasioso condensam uma contundente questão sobre a vida na modernidade, seja ela humana ou animal.

Como argumenta Giorgio Agamben (2007), a diferença entre humano e animal precisa ser incessantemente (re)produzida na cultura ocidental por um "dispositivo irónico" (p. 63) que é articulado de formas diferentes mas simétricas entre antigos e modernos: 
Tenemos asi la máquina antropológica de los modernos. Ella funciona [...] excluyendo de si como no (todavía) humano un ya humano, esto es, animalizando lo humano, aislando lo no-humano en el hombre: Homo alalus, o el hombre-simio. [...] Exactamente simétrico es el funcionamiento de la máquina de los antiguos. Si en la máquina de los modernos, el afuera se produce mediante la exclusión de un adentro y lo inhumano, animalizando el humano, en la de los antiguos el adentro se obtiene mediante la inclusión de un afuera, el no-hombre a través de la humanización de un animal: el mono-hombre, el enfant sauvage o el Homo ferus, peno, también y sobretodo, el esclovo, el bárbaro, el extranjero como figuras de un animal con formas humanas. (AGAMBEN, 2007; p. 75-76)

Em relação ao traçado da fronteira entre humano e animal, as narrativas de Tarzan eituc! ’çam as formas antiga e moderna de produção da diferença, sendo que a máquina antropológica dos modernos enquadra os elementos da máquina antropológica dos antigos. Na figura de Tarzan estão condensados discursos difusos em outros elementos formais e em outros componentes de suas narrativas: Tarzan é, em vários momentos, tanto o homem-macaco quanto o macaco-homem, e uma figura como Chita, a chimpanzé que acompanha Tarzan em vários dos filmes, condensa a referência ambígua à humanização do animal, ao "macaco-homem", que acompanha a referência à animalização do humano, tematizada na personagem de Tarzan como "homemmacaco" e reiterada na produção da diferença colonial através da versão filmica do zoológico humano. Assim, estão articuladas as versões antiga e moderna da máquina antropológica ocidental. Isso torna Tarzan e seu universo um locus privilegiado de interrogação da máquina antropológica, de questionamento da maneira pela qual a máquina moderna opera a apropriação de elementos da máquina antiga e de como se dá a articulação da máquina antropológica em termos sócio-políticos.

Dentro do horizonte sócio-político da interrogação da máquina antropológica nas narrativas de Tarzan, é notável que a diferença entre humano e animal é demarcada de forma articulada, embora não livre de tensões, 
O caminho, a experiência e a aventura Marcelo Rodrigues Souza Ribeiro

ao traçado da diferença colonial. É no movimento de demarcar ambas as fronteiras que as narrativas de Tarzan comentam a ansiedade moderna em relação à destruição da experiência. Tudo se passa como se essa ansiedade pudesse ser apaziguada com o traçado firme das fronteiras entre humano e animal, civlizado e primitivo (e, para todos os efeitos, homem e mulher, branco e negro etc.). No sonho projetado em torno de Tarzan, uma certa humanidade parece pretender reencontrar a si mesma e assegurar-se da fronteira que a separa da animalidade, construindo em fantasia "uma existência que se basta a si mesma", nas palavras de Benjamin.

Se o sonho segue o cansaço, se a fantasia responde a uma vida diária infinitamente complicada e fatigante, como argumenta Benjamin, sonhar uma diferença segura entre humano e animal, como as aventuras de Tarzan fazem, é uma resposta à ansiedade em torno do "frágil e minúsculo corpo humano" de que fala Benjamin, à condição da vida na modernidade como vida nua, como objeto de uma biopolítica (cf. AGAMBEN, 2002). O sonho, porém, não se dá como um complemento. Sobra um resíduo sintomático. $O$ trabalho de sonho - orientando-se pela dupla demarcação da diferença entre humano e animal e da diferença colonial - produz também um excesso que resta inassimilável, uma zona de indeterminação. A suplementaridade que opera no traçado da aventura, entretecendo modernidade e colonialidade como condições de existência, opera também no traçado da biopolítica, entretecendo o humano e o animal no próprio movimento de separá-los. Como tornar legível essa dupla suplementaridade que constitui a relação das narrativas de Tarzan com a modernidade - tanto o suplemento experiencial da aventura quanto o suplemento vital da máquina antropológica?

Sem responder a essa pergunta, encerro, programaticamente, com Agamben:

Ambas máquinas pueden funcionar tan sólo instituyendo en su centro una zona de indiferencia en la que debe producirse - como un missing link siempre faltante porque ya virtualmente presente - la articulación entre lo humano y lo animal, el hombre y el no-hombre, el hablante y el viviente. Como todo espacio de excepción, esta zona está en verdad perfectamente vacia, y lo verdaderamente humano que debe producirse es tan sólo el lugar de una decisión incesantemente actualizada, 


\section{HUMANAS}

en la que las cesuras y sus rearticulaciones están siempre de nuevo deslocalizadas y desplazadas. Lo que debería obtenerse asi no es, de todos modos, una vida animal ni una vida humana, sino sólo una vida separada y excluída de si misma, tan sólo una vida desnuda.

$Y$ frente a esta figura extrema de lo humano y de lo inhumano, no se trata tanto de preguntarse cuál de las dos máquinas (o de las dos variantes de la misma máquina) es mejor o más eficaz - o, más bien, menos sangrienta y letal -, como de comprender su funcionamiento para poder, eventualmente, detenerla. (AGAMBEN, 2007; p. 76)

\section{Referências bibliográficas}

AGAMBEN, G. Infância e história: destruição da experiência e origem da história. Tradução de Henrique Burigo. Belo Horizonte: Editora UFMG 2005.

AGAMBEN, G. Homo sacer: o poder soberano e a vida nua I. Tradução de Henrique Burigo. Belo Horizonte: Editora UFMG 2002.

AGAMBEN, G Lo abierto - El hombre y el animal. Buenos Aires: Adriana Hidalgo, 2007.

BANCEL, N.; BLANCHARD, P.; BOËTSCH, G.; DEROO, E.; LEMAIRE, S. Zoos humains: au temps des exhibitions humaines. Paris: La Découverte, 2004.

BENJAMIN, W. Experiência e pobreza. In: Magia e técnica, arte e politica: ensaios sobre literatura e história da cultura (Obras Escolhidas, v. 1). São Paulo: Brasiliense, 1994.

BRADBURD, D. Chapter 3: Adventure in the Zeitgeist, Adventures in reality: Simmel, Tarzan and Beyond. In: VIVANCO, L. A.; GORDON, R. J. Tarzan was an eco-tourist... and other tales in the Anthropology of adventure. Nova York, Oxford: Berghahn Books, 2006. 
O caminho, a experiência e a aventura

Marcelo Rodrigues Souza Ribeiro

FERREIRA, J. Da vida ao tempo: Simmel e a construção da subjetividade no mundo moderno. Revista Brasileira de Ciências Sociais. V. 15, n. 44, p. 103-117, outubro, 2000.

GINZBURG, C. Sinais: raízes de um paradigma indiciário. In: Mitos, emblemas, sinais: morfologia e História. São Paulo: Companhia das Letras, 1990.

GORDON, R. J. Chapter 1: introduction. In: VIVANCO, Luis A.; GORDON, Robert J. Tarzan was an eco-tourist... and other tales in the Anthropology of adventure. Nova York, Oxford: Berghahn Books, 2006.

JOHSNON, O. Casei-me com a aventura - a vida e as aventuras de Martin e Osa Johnson. Rio de Janeiro: Livraria José Olympio, 1957.

SIMMEL, G. A ponte e a porta. (Tradução de Simone Maldonado.) Politica e trabalho. N. 12, p. 10-14. PPGS/UFPB, 1996.

SIMMEL, G. O conceito e a tragédia da cultura. In: SOUZA, J.; ÖELZE, B. Simmel e a modernidade. Brasília: Universidade de Brasília, 1998.

SIMMEL, G. A aventura. In: SOUZA, J.; ÖELZE, B. Simmel e a modernidade. Brasília: Editora Universidade de Brasília, 1998.

THOMAS, N. Colonialism's culture: anthropology, travel and government. Princeton: Princeton University Press, 1994.

VIVANCO, L. A.; GORDON, R. J. Tarzan was an eco-tourist... and other tales in the Anthropology of adventure. Nova York, Oxford: Berghahn, 2006. 